\title{
Effect of wound infiltration with bupivacaine on pulmonary function after elective lower abdominal operations
}

\author{
*Ige OA, Bolaji BO, Kolawole IK \\ Department of Anaesthesia, University of Ilorin /University of Ilorin Teaching Hospital, Ilorin, Nigeria
}

\begin{abstract}
Background: Subcutaneous or intrafascial wound infiltration of local anaesthetic with systemic opioids has been shown to enhance patient comfort with improved analgesia and reduced opioid requirements. .

Objective: To demonstrate improved pulmonary function when postoperative analgesia was provided by combined bupivacaine wound infiltration and systemic opioid.

Methods: In a prospective, randomized, placebo-controlled study, 46 patients (23 per group) scheduled for elective gynaecological surgery under general anaesthesia had subcutaneous and intrafascial wound infiltration of $40 \mathrm{ml}, 0.25 \%$ bupivacaine (study patients) or $40 \mathrm{ml} \mathrm{0.9 \%} \mathrm{saline} \mathrm{(control)} \mathrm{just} \mathrm{before} \mathrm{the} \mathrm{end} \mathrm{of} \mathrm{surgery.} \mathrm{Forced} \mathrm{vital} \mathrm{capacity} \mathrm{(FVC),} \mathrm{forced}$ expiratory volume in 1 second (FEV1) and peak expiratory flow rate (PEFR) were done before surgery and at 6, 12 and 24 hours postoperatively. Student's T and chi-square tests were used for tests of significance set at $\mathrm{P}<0.05$.

Postoperative analgesia was provided with intramuscular morphine $0.15 \mathrm{mg} / \mathrm{kg}$ 4hourly and $10 \mathrm{mg} / \mathrm{kg}$ of intravenous paracetamol as rescue analgesia.

Results: PEFR, FVC and FEV1 were reduced in both the control and study groups but the reduction was greater in the control group.

Conclusion: Bupivacaine wound infiltration produced statistically significant elevations in pulmonary function tests results at all assessment periods.

Key words: Bupivacaine, postoperative, pulmonary function, wound infiltration

African Health Sciences 2013; 13(3): 756 - 761 http://dx.doi.org/10.4314/ahs.v13i3.34
\end{abstract}

\section{Introduction}

Postoperative pulmonary dysfunction is commonly seen after abdominal and thoracic operations. This leads to an increase in morbidity among surgical patients ${ }^{1}$. The pulmonary abnormalities usually seen include reduced lung volumes, hypoxaemia and atelectasis. Vital capacity and functional residual capacity are also reduced ${ }^{1}$. Hypoxia may impair wound healing and in elderly patients, it can cause cognitive dysfunction. Atelectasis predisposes patients to chest infection and subsequent respiratory failure.

It has been shown that uncontrolled postoperative pain is the most important factor responsible for these respiratory changes ${ }^{2}$. Unfortunately, pain remains a significant problem following surgical operations in our environment ${ }^{3,4}$. The respiratory changes caused by pain can be detected by spirometry and measurement of the peak

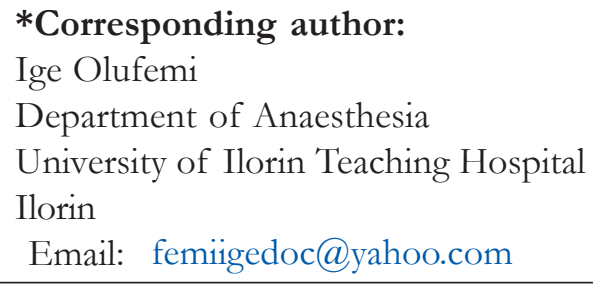

expiratory flow rate. These include a reduction in forced expiratory volume in one second (FEV1), the ratio of forced expiratory volume in one second to forced vital capacity (FEV1/FVC) and peak expiratory flow rate (PEFR) ${ }^{2}$.

The beneficial effects of a combination of subcutaneous or intrafascial infiltration of local anaesthetic with systemic opioid administration have been demonstrated with improved analgesia, enhanced patient comfort, reduced opioid requirements ts, $^{5,7,8}$ and improved postoperative pulmonary function in upper abdominal surgeries ${ }^{9,10}$.

The aim of the study was to compare pulmonary function tests following lower abdominal surgeries when postoperative analgesia was provided by combined bupivacaine wound infiltration and systemic opioid with those obtained when only systemic opioid was used.

\section{Methods}

After obtaining ethics committee approval, a prospective, randomized, double blind, placebocontrolled study was carried out at the University of Ilorin Teaching Hospital, Ilorin, Nigeria from 
April to October 2010. Forty-six patients undergoing elective lower abdominal gynaecologic surgery were recruited into the study.

Exclusion criteria: these are patients refusal to participate in the study, age $<16$ or $>65$ years, American Society of Anesthesiologist's Classification (ASA) class $>$ II, a history of drug abuse. Others are regular medication with non-steriodal antiinflammatory drugs (NSAIDS) or opioids, diabetes mellitus, morbid obesity and inability to cooperate with instruction from language barrier or psychiatric illness.

Each patient was assessed the night before surgery. Explanations and demonstrations on the verbal rating scale for scoring pain validated among both educated and uneducated African subjects ${ }^{11}$ (appendix IV), the Micro spirometer (Micro Medical Ltd, Rochester Kent England) and the Wright's peak flowmeter (Omron, PF9940, Lake Forest, Illinois USA) for pulmonary function testing were given to the patients. Informed consent was obtained from all patients and a research assistant randomly allocated the patients to one of two groups (study and control) by balloting. The patients were also instructed to request for analgesia when they felt pain postoperatively. Forced vital capacity (FVC), forced expiratory volume in 1 second (FEV1) and peak expiratory flow rate (PEFR) were done to obtain baseline values before surgery.

\section{Anaesthesia}

The subjects were sedated with oral diazepam $10 \mathrm{mg}$ the night before and premedicated with another 10 $\mathrm{mg}$ oral diazepam on the morning of surgery, 2 hours before anaesthesia. A standard general anaesthetic was administered. Intravenous access was secured with $18 \mathrm{G}$ cannula and a multiparameter patient monitor (Nelcor-Puritan-Bennett, NBP-4000, Boulder Colorado USA) was used to monitor blood pressure, heart rate, arterial oxygen saturation and the electrocardiogram intraoperatively. The patients were preoxygenated for three minutes and anaesthesia was induced with $5 \mathrm{mg} / \mathrm{kg}$ of sodium thiopental. Suxamethonium $1 \mathrm{mg} / \mathrm{kg}$ was administered intravenously to facilitate endotracheal intubation. Muscle paralysis was maintained with pancuronium $0.1 \mathrm{mg} / \mathrm{kg}$ and supplemental doses were given as required. The patients were ventilated manually with $66 \%$ nitrous oxide in oxygen supplemented with $0.5-1 \%$ halothane or isoflurane using a Bain anaesthetic breathing system. Intraoperative analgesia was provided with $100 \mu \mathrm{g}$ of fentanyl given intravenously at induction and supplemental doses as required. Before the end of surgery, after the closure of the peritoneum, patients in the study group received subcutaneous and intrafascial infiltration with $40 \mathrm{ml}$ of $0.25 \%$ bupivacaine about $1 \mathrm{~cm}$ from the wound edges while the control group received $40 \mathrm{ml}$ of $0.9 \%$ saline similarly administered by the surgeon who was blinded to the agent in use. The solutions for infiltration were prepared and coded by a resident anaesthetist who took no further part in the study. At the end of the surgery muscle paralysis was reversed with $0.04 \mathrm{mg} / \mathrm{kg}$ of neostigmine administered in combination with $0.02 \mathrm{mg} / \mathrm{kg}$ of atropine.

\section{Analgesia}

Postoperative analgesia was provided with intramuscular morphine $0.15 \mathrm{mg} / \mathrm{kg}$ 4hourly. Morphine was only given to patients with a verbal rating score $>1$, systolic blood pressure of $100 \mathrm{mmHg}$ or more, respiratory rate of more than 8 cycles per minute and sedation score of $<3$ (Appendix V). Patients who experienced pain despite maximal dosage of morphine were given $10 \mathrm{mg}$ / $\mathrm{kg}$ of intravenous paracetamol in an infusion of normal saline over $15 \mathrm{mins}$ as rescue analgesia.

\section{Pulmonary function testing}

Pulmonary function testing was done before surgery for baseline results and postoperatively at 6,12 and 24 hours by a senior registrar in the department of anaesthesia who was also blinded to the patient groups. The patients were positioned reclining at forty-five degrees to the horizontal. The micro spirometer was used to measure FVC and $\mathrm{FEV}_{1}$. The patients were asked to breathe in maximally to total lung capacity and then expire as hard and fast as possible into the spirometer until they could force no more air out of their lungs. PEFR was measured with a Wright's peak flow meter. During the peak flow measurement the patients were asked to take a full inspiration and then blow forcefully into the Wright's peak flow meter which were held horizontally while the lips were tightly clasped around the mouthpiece. Three readings were taken at each spirometric and peak flow measurement and the maximum reading was recorded.

In order to detect a difference of $22 \%$ in the incidence of pain from a previous study ${ }^{7}$ between the two groups, a power analysis determined that 
19 patients would be needed in each study group (alpha 0.05, beta 0.2). To make up for attrition rate of $10 \%, 23$ patients were recruited for each group

\section{Data analysis}

Data generated from this study were expressed as frequencies or proportions of total, means and standard deviations. Tests of significance were analyzed with student's $\mathrm{T}$ test and chi-squared test using the computer software package EPI-info version 2002. A p-value of less than 0.05 was considered statistically significant.

\section{Results}

A total number of forty-six (46) patients were studied over a six month period. Six patients were excluded from the study. Three (3) had nonsteroidal anti-inflammatory drugs administered by attending doctors who were not aware they were study patients, 2 opted out of the study and 1 had intraoperative hypotension resulting from haemorrhage which was not effectively corrected before the end of surgery. The remaining forty patients were included in the study. Twenty patients had their wounds infiltrated with $40 \mathrm{mls}$ of $0.25 \%$ bupivacaine while another twenty had their wounds infiltrated with an equal volume of saline. The patients in the control group were significantly younger than those in the study group $(p=0.01)$ while the PEFR, FVC and FeV1 were significantly higher in the study group than in the control group.

Table 1: Demographic data

\begin{tabular}{lllll}
\hline & Study & Control & t value & p value \\
\hline Mean age & $44.75(9.0)$ & $38.25(7.7)$ & 2.4542 & 0.0189 \\
Weight & $67.7(10.3)$ & $66.5(6.72)$ & 0.4364 & 0.6654 \\
\hline
\end{tabular}




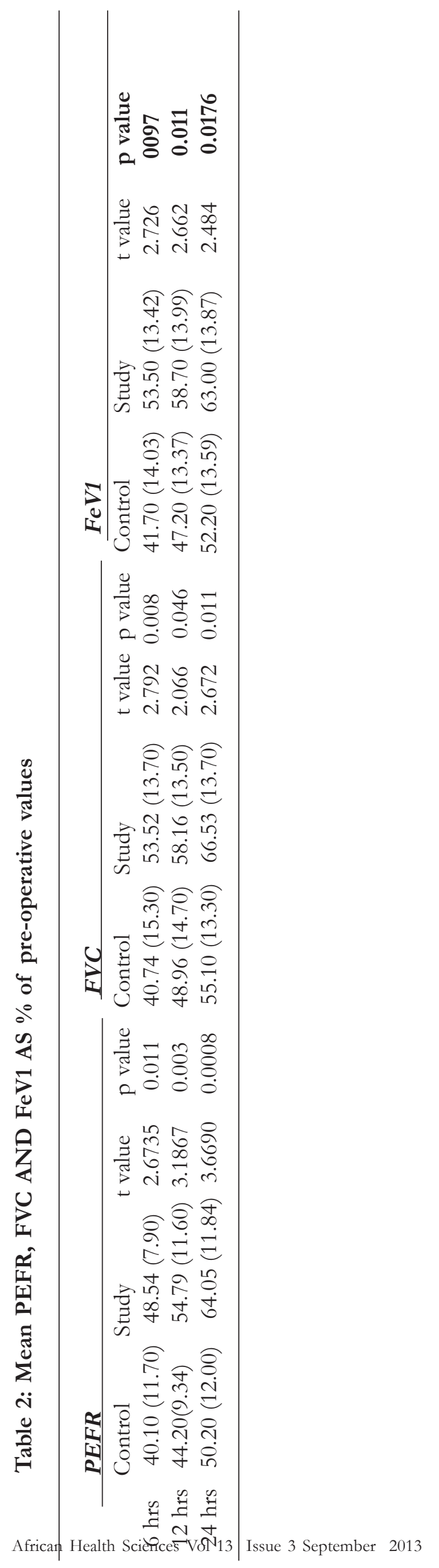

\section{Discussion}

This study has tested the efficacy of a combination of intramuscular opioid administration with local anaesthetic wound infiltration in reducing the deterioration in post-operative pulmonary function commonly seen after lower abdominal surgeries.

The mean weight of patients in this study was $67.1 \mathrm{~kg}$. On the average $1.49 \mathrm{mg} / \mathrm{kg}$ of bupivacaine was infiltrated into each patient's wound. This is within the recommended dose range for plain bupivacaine ${ }^{12}$. Another important consideration is the volume and concentration of local anesthetic delivered at the surgical site. A large volume of solution ( $40 \mathrm{ml}$ of $0.25 \%$ ) was chosen to ensure adequate spread throughout the wound layers.

Of greater importance may be the technique used for administration of local anaesthesia. This study was probably successful in detecting an improvement in post-operative pulmonary function because both the subcutaneous and fascial layers of the wound were infiltrated with bupivacaine. A study by Yndgaard et $\mathrm{al}^{13}$ showed that lidocaine was more effective when applied subfascially compared with subcutaneous infiltration after hernia repair. Tan et $\mathrm{al}^{8}$ also found that selective infiltration of the rectus abdominis muscle resulted in a reduction of pain scores and morphine consumption. They concluded that the rectus muscle is an important origin of pain in the early post-operative period after hysterectomy.

Pulmonary function tests at six hours postoperatively showed that PEFR had dropped to $40.10 \%$, FVC dropped to $40.74 \%$ while FEV1 had dropped to $41.70 \%$ in the control group, i.e. about $40 \%$ of the pre-operative value. These values are similar to those of Patel et $\mathrm{al}^{9}$ who found that postoperative FVC and FEV1 values had dropped to $50 \%$ of pre-operative levels after surgery. Since the influence of diaphragmatic dysfunction is minimal in lower abdominal surgeries, it can be assumed that this marked reduction in spirometric results was predominately due to post-operative pain. This suggests that incisional pain is a significant cause of post-operative pulmonary dysfunction.

In this study, it was found that bupivacaine wound infiltration significantly reduced postoperative pulmonary dysfunction at six hours after surgery. Although all pulmonary function tests were reduced six hours after surgery, the reduction in the control group was significantly greater than in the study group. [PEFR $(p=0.011)$, FVC $(p=0.008)$ and FEV1 $(p=0.0097)]$. In the study by Egan et $\mathrm{al}^{14}$ where intrafascial bupivacaine wound infiltration was 
given to patients undergoing elective laparotomy, no difference was found in pulmonary function tests among those who had wound infiltration and those who did not. This may be because only fascial infiltration was done, bupivacaine infiltration of both the fascial and subcutaneous tissues as was done in this study probably resulted in better analgesia.

In all three pulmonary function tests, the values steadily increased with time. The values for PEFR, FVC and FEV 1 were significantly higher in the study group than in the control group. This is not surprising as effective muscular function is needed to perform the pulmonary function tests. This muscular activity is disrupted by the surgical incision that breaks muscle fibres and by the restrictive effect of abdominal pain. The effectiveness of local anaesthetic infiltration in reducing the somatic pain experienced at a surgical wound would be expected to allow better muscular activity leading to improved pulmonary function test results.

However, at twenty four (24) hours the spirometric values had not risen to $100 \%$ of their pre-operative value. In the control group spirometric values had recovered to $50-55 \%$ of pre-operative values, while in the study group it was $62-66 \%$. Therefore, it takes more than 24 hrs for full recovery of pulmonary function as assessed by spirometry to take place. Dureuil et $\mathrm{a}^{15}$ in their study found that vital capacity returned to normal range within 3 days in patients who underwent lower abdominal surgeries.

\section{Limitations}

Opioid analgesia was provided as intermittent intramuscular injections. It would have been preferable to use a patient controlled analgesia system. This was not possible because the facility was not available in this centre at the time the study was carried out.

\section{Conclusion}

The results of pulmonary function tests demonstrated statistically significant elevations in PEFR, FVC and FEV1 values at all the assessment periods in patients who had their wounds infiltrated with bupivacaine. Wound infiltration with bupivacaine serves to increase the options available for the alleviation of postoperative pulmonary dysfunction.

\section{Recommendations}

Based on the findings in this study, we recommend the routine use of bupivacaine wound infiltration to ameliorate the post-operative pulmonary dysfunction seen after lower abdominal surgery. This may be more important in patients with respiratory disease undergoing abdominal surgery. It reduces dynamic pain thus enabling patients to cough better. This improves sputum clearance and prevents or alleviates chest infection. It should be used to improve postoperative pain in places where the resources are limited.

\section{References}

1. Hall JC, Tarala RA, Hall JL and Mander J. A multivariate analysis of the risk of pulmonary complications after laparotomy. Chest. 1991; 99: 923-927

2. Sydow FW. The influence of anaesthesia and postoperative analgesic management on lung function. Acta Chirurgica scandinavica 1988;550: 159-168.

3. Kolawole IK, Fawole AA. Postoperative pain management following caesarean section in University of Ilorin Teaching Hospital (UITH), Ilorin, Nigeria. West Afr J Med. 2003; 22: 305309.

4. Ocitti EF, Adwork JA. Postoperative management of pain following major abdominal and thoracic operations. East Afr. Med. J. 2000; 77: 299-302.

5. Hanniball K, Galasius H. Bupivacaine reduces early and late opioid requirements after hysterectomy. Anesth Analg. 1996; 83:376-381.

6. Johansson B. Glise H, Hallerback B, Dalman P, Kristoffersson A. Preoperative local infiltration with ropivacaine for postoperative pain relief after cholecystectomy. Anesth Analg. 1994; 78:210-214.

7. Kushimo OT, Bode CO, Adedokun BO, Desalu I. Incisional infiltration of bupivacaine for postoperative analgesia in children. Afr. J. Anaesth. Int. C, 2001; 4: 13-15.

8. Tan CH, FAMS KY. Kun MK, Onsiong MK, Chan BN, Chiu WKY, Tai CM Postincisional local anaesthetic infiltration of the rectus muscle decreases early pain and morphine consumption after abdominal hysterectomy. Acute Pain. 2002; 4: 49-52.

9. Patel JM, Lanzafame RJ, Williams JS, Mullen BV, Hinshaw JR. The effect of incisional infiltration 
of bupivacaine hydrochloride upon pulmonary functions, atelectasis and narcotic need following elective cholecystectomy. Surg Gynecol Obstet. 1983; 4: 338-40.

10. Raetzell M, Maier C, Schröder D, Wulf H. Intraperitoneal application of bupivacaine during laparoscopic cholecystectomy, risk or benefit? Anesth Analg. 1995; 81: 967-972.

11. Soyannwo OA, Amanor-Boadu SD, Sanya AO, Gureje O. Pain assessment in Nigerians - Visual analogue scale and verbal rating scale compared. West Afr. J. Med. 2000; 4:242-245

12. Bukwirwa HW. Toxicity from local anaesthetic drugs. Update in Anaesthesia 1999; 10: 50-51
13. Yndgaard S, Holst P, Bjerre-Jepsen K, Thomsen CB, Struckmann J, Mogensen T. Subcutaneously versus subfascially administered lidocaine in pain treatment after inguinal herniotomy. Anesth Analg. 1994;79:324-7.

14. Egan TM, Herman SJ, Doucette EJ, Normand SL, McLeod RS. A randomized, controlled trial to determine the effectiveness of fascial infiltration of bupivacaine in preventing respiratory complications after elective abdominal surgery. Surgery. 1988;104:734-40.

15. Dureuil B, Cantineau JP, Desmonts JM. Effects of upper or lower abdominal surgery on diaphragmatic function. $\mathrm{Br}$ J. Anaesth. 1987; 59:1230-5 